\title{
Gender difference and determinants of C-reactive protein level in Korean adults
}

\author{
Yong-Jae Lee ${ }^{1}$, Jung-Hyun Lee ${ }^{2}$, Youn-Ho \\ Shin $^{3}$, Jong-Koo Kim ${ }^{4}$, Hye-Ree Lee ${ }^{1}$ \\ and Duk-Chul Lee ${ }^{1, *}$ \\ ${ }^{1}$ Department of Family Medicine, Yonsei University \\ College of Medicine, Seoul, Korea \\ 2 Department of Health Promotion Center, Gangnam \\ Severance Hospital, Yonsei University College \\ of Medicine, Seoul, Korea \\ ${ }^{3}$ Department of Pediatrics, Pochon CHA University \\ College of Medicine, Seoul, Korea \\ ${ }^{4}$ Department of Family Medicine, Yonsei University \\ Wonju College of Medicine, Wonju, Korea
}

\begin{abstract}
Background: C-reactive protein (CRP) has emerged as an important predictor for cardiovascular disease (CVD). To facilitate clinical and public health interventions, CRP thresholds have been defined as follows: low-risk ( $<1.0 \mathrm{mg} / \mathrm{L})$, average-risk (1.0-3.0 mg/L), and high-risk (>3.0 mg/L). However, these cut-off thresholds are based on distributions in Western populations, and do not distinguish between men and women.

Methods: We examined CRP distribution, gender difference, and determinants of CRP concentrations ranging from $0.02 \mathrm{mg} / \mathrm{L}$ to $10.0 \mathrm{mg} / \mathrm{L}$, in 4923 Korean adults (2248 men; 2675 women) who received health checkups at Gangnam Severance Hospital from March 2006 to May 2007.

Results: The distribution of CRP was highly skewed toward lower concentrations. CRP was higher in men than women, and the cut-off thresholds for the highrisk tertile of CRP concentrations corresponded to $1.01 \mathrm{mg} / \mathrm{L}$ in men and $0.62 \mathrm{mg} / \mathrm{L}$ in women, based on the current study population. Age, male gender, cigarette smoking, physical activity, body mass index, total cholesterol, high density lipoprotein cholesterol, $\gamma$-glutamyltransferase, and uric acid were independently associated with CRP concentrations.

Conclusions: CRP distribution and gender difference in Korean adults were found to be different from previous Western studies, although similar risk factors influence CRP concentrations. Our results suggest that ethnicity and gender specific cut-off thresholds

\footnotetext{
*Corresponding author: Duk-Chul Lee, MD, PhD, Department of Family Medicine, Yonsei University College of Medicine, 134 Sinchon-dong, Seodaemun-gu, Seoul, Korea

Phone: +82-2-2228-2331, Fax: +82-2-362-2473

E-mail: faith@yuhs.ac

Received January 24, 2009; accepted April 20, 2009
}

for CRP concentrations should be taken into consideration in CVD risk assessment.

Clin Chem Lab Med 2009;47:863-9.

Keywords: cardiovascular disease (CVD); C-reactive protein (CRP); gender difference.

\section{Introduction}

Increasing evidence reveals that arterial inflammation plays a key role in the process of atherosclerosis and cardiovascular disease (CVD) (1, 2). Recent studies have shown that $\mathrm{C}$-reactive protein (CRP) is not just an indicator of current infection, but also a useful predictor of CVD incidence and mortality (3-5). Thus, early detection of a continuous increase in CRP concentrations may be useful in predicting subsequent development of CVD. Recently, the Centers for Disease Control and Prevention (CDC) and American Heart Association (AHA) recommended that measurement of CRP level is useful to assess risk of primary and secondary cardiovascular events (6). To facilitate clinical and public health interventions, CRP thresholds have been defined as follows: low-risk $(<1.0$ $\mathrm{mg} / \mathrm{L})$, average-risk (1.0-3.0 mg/L), and high-risk (>3.0 $\mathrm{mg} / \mathrm{L})$. These correspond to approximate tertiles of CRP in the US adult population (6). Despite the cardiovascular health implications of CRP, the recommended cut-off points of the CDC/AHA are based predominantly on Western populations, and do not make a distinction between men and women. Gender differences in CRP concentrations is currently a controversial topic. Some epidemiological studies have reported similar values for CRP in both men and women $(7,8)$, whereas others have shown higher concentrations in men (9) or women only $(10,11)$.

On the basis of these considerations, it is critical to know the characteristics and conditions associated with increased or decreased CRP concentrations in specific populations, but relatively little information is known about East Asians. Koreans are a group of East Asians with ethnic homogeneity and lower body mass index (BMI) compared to Westerners. In addition, the smoking rate for Korean women is $<5 \%$, which is strikingly lower than for Korean men (12). Indeed, different ethnicity and lifestyle factors of Koreans may affect the inflammatory response in different ways (13-15).

Therefore, we examined gender difference and determinants of CRP concentrations in 4923 Korean adults (2248 men; 2675 women; aged $20-75$ years) who received health checkups at Gangham Severance Hospital from March 2006 to May 2007. 


\section{Materials and methods}

\section{Study population}

This study is based on the Health Risk Assessment Study (HERAS) cohort. The HERAS consisted of 5342 subjects (2347 men, 2995 women) who visited voluntarily the Health Promotion Center, Gangnam Severance Hospital, for a routine health checkup. This cohort aims to characterize the prevalence and distribution of CVD risk factors and explore surrogate markers for CVD in Korean adults (16). Between March 2006 and May 2007, 6451 individuals gave written informed consent to the study protocol at the beginning and at follow-up. The study was approved by the Institutional Review Board of Yonsei University College of Medicine, Seoul, Korea. Subjects meeting any of the following criteria were excluded: CRP concentrations of more than $10 \mathrm{mg} / \mathrm{L}$ for ruling out potential ongoing infection or inflammatory disorders $(n=38)$; a history of cancer, ischemic heart disease, stroke, respiratory, renal, liver, and rheumatologic disease $(n=158)$; and use of oral contraceptives or hormone replacement therapy $(n=223)$. After exclusion, the remaining 4923 subjects (2248 men; 2675 women; aged $20-75$ years), whose CRP concentrations ranged from $0.02-10.0 \mathrm{mg} / \mathrm{L}$, were included in the final analysis.

\section{Data collection}

Physical examinations were performed by trained medical staff according to a standardized procedure. Body weight and height were measured in subjects wearing light indoor clothing and without shoes to the nearest $0.1 \mathrm{~kg}$ and $0.1 \mathrm{~cm}$, respectively. BMI was calculated as the ratio of weight $(\mathrm{kg}) /$ height $\left(\mathrm{m}^{2}\right)$. Participants were asked about health related behaviors including cigarette smoking, alcohol consumption, and physical activity as well as current treatment for any type of disease. If subjects were receiving treatment, they were asked for the date of diagnosis of disease and a list of medications taken. Following a 12-h overnight fast, blood samples were obtained from the antecubital vein of each subject. High sensitivity CRP concentrations were measured using the Roche/Hitachi 912 System (Roche Diagnostics, Indianapolis, IN, USA), a latex-enhanced immunoturbidimetric method with a lower limit of detection of 0.02 $\mathrm{mg} / \mathrm{L}$. The normal range of CRP concentrations could be different among different ethnic groups and the upper reference range limit of CRP in Korean adults is $6.0 \mathrm{mg} / \mathrm{L}$. Fasting plasma glucose (FPG), total cholesterol, triglyceride, high density lipoprotein (HDL) cholesterol, aspartate aminotransferase (AST), alanine aminotransferase (ALT), $\gamma$-glutamyltransferase (GGT), and uric acid were measured using a Hitachi 7600-110 Chemistry analyzer (Hitachi, Tokyo, Japan). Diabetes was defined as a self-reported history of the disorder or an FPG concentration $\geq 7.0 \mathrm{mmol} / \mathrm{L}$. Hypertension was defined as a self-reported history of the disorder, systolic blood pressure (SBP) $\geq 140 \mathrm{~mm} \mathrm{Hg}$, or diastolic blood pressure $(\mathrm{DBP}) \geq 90 \mathrm{~mm} \mathrm{Hg}$.

\section{Statistical analysis}

Clinical and chemical characteristics of the study population were summarized. Comparisons between men and women were performed using Student's t-test for continuous variables, and the $\chi^{2}$-test was used for categorical variables. The median concentration of CRP between men and women was tested using the Wilcoxon-Rank sum test. Age and multivariate adjusted geometric mean values of CRP concentrations in men and women were calculated using analysis of covariance (ANCOVA). To confirm that gender differences in CRP were independent of the effects of smoking, we also compared multivariate adjusted geometric mean values of CRP concentrations between men and women through subgroup analyses of non-smokers using ANCOVA test. We determined the percentage of people classified as being lowrisk ( $<1 \mathrm{mg} / \mathrm{L})$, intermediate-risk (1-3 $\mathrm{mg} / \mathrm{L})$, and high-risk ( $>3 \mathrm{mg} / \mathrm{L}$ ) using the CRP risk criteria of the CDC/AHA scientific statement (6). Due to skewness, CRP was log transformed prior to statistical analyses. Pearson correlation coefficients were determined for CRP concentrations in men and women vs. age, BMI, cigarette smoking, alcohol use, physical activity, SBP, DBP, FPG, total cholesterol, triglyceride, HDL cholesterol, and uric acid. To examine independent correlates of CRP, a multivariate linear regression model was constructed with log-transformed CRP as the dependent variable. All analyses were performed using SAS statistical software, version 9.1 (SAS Institute Inc, Cary, NC, USA). All statistical tests were two-sided and a $p<0.05$ was used for statistical significance.

\section{Results}

Table 1 shows the demographics of the study population, which consisted of 2248 men and 2675 women. The mean BMI $\left(\mathrm{kg} / \mathrm{m}^{2}\right)$ was 24.7 for men and 23.0 for women. Blood pressure, FPG, total cholesterol, triglyceride, and liver enzymes were higher in men compared with women. Cigarette smoking and alcohol use were substantially more common in men than in women, and the percentage of hypertension and diabetes was also more prevalent in men.

The overall distribution of CRP according to age group and gender is shown in Table 2. The median value of CRP increased with age in both men and women. Men had higher CRP concentrations than women (median, $0.72 \mathrm{mg} / \mathrm{L}$ vs. $0.45 \mathrm{mg} / \mathrm{L} ; \mathrm{p}<0.001$ ), and this pattern was observed for all age groups. Gender differences in CRP concentrations remained valid after adjusting for age, BMI, smoking status, alcohol intake, physical activity, blood pressure, FPG, total cholesterol, triglyceride, and HDL cholesterol. The multivariate adjusted geometric mean CRP concentrations were $0.67 \mathrm{mg} / \mathrm{L}$ in men and $0.57 \mathrm{mg} / \mathrm{L}$ in women $(p<0.001$, Figure 1). However, the current study failed to show any significant gender differences in CRP concentrations through subgroup analyses of non-smokers. After adjustment for age, BMI, alcohol intake, physical activity, blood pressure, FPG, total cholesterol, triglyceride and HDL cholesterol, the gender difference was attenuated and not significant in subgroup analyses of non-smokers $(p=0.090)$.

The proportion of subjects with high-risk CRP concentrations according to the CDC/AHA cut-off threshold of $>3.0 \mathrm{mg} / \mathrm{L}$ was $8.7 \%$ in men and $5.9 \%$ in women. Similarly, the proportion of subjects with intermediate-risk CRP concentrations of $1.0-3.0 \mathrm{mg} / \mathrm{L}$ was also higher in men compared to women $(28.3 \%$ vs. $18.1 \%$ ) (Table 3).

Pearson and Spearman correlation results are shown in Table 4. Log transformed CRP concentrations correlated significantly with age, BMI, blood pressure, FPG, uric acid, total cholesterol, triglyceride, 
Table 1 Demographic and biochemical characteristics of the study populationa.

\begin{tabular}{|c|c|c|c|}
\hline & Men & Women & $p-$ Value $^{\mathrm{b}}$ \\
\hline $\mathrm{n}$ & 2248 & 2675 & \\
\hline Age, years & $46.6 \pm 10.1$ & $45.3 \pm 10.7$ & $<0.001$ \\
\hline $\mathrm{BMI}, \mathrm{kg} / \mathrm{m}^{2}$ & $24.7 \pm 2.9$ & $23.2 \pm 3.2$ & $<0.001$ \\
\hline $\mathrm{SBP}, \mathrm{mm} \mathrm{Hg}$ & $125.9 \pm 15.3$ & $121.3 \pm 16.0$ & $<0.001$ \\
\hline $\mathrm{DBP}, \mathrm{mm} \mathrm{Hg}$ & $78.7 \pm 10.1$ & $74.9 \pm 10.3$ & $<0.001$ \\
\hline $\mathrm{FPG}, \mathrm{mmol} / \mathrm{L}$ & $5.32 \pm 1.08$ & $4.93 \pm 0.81$ & $<0.001$ \\
\hline Total cholesterol, mmol/L & $4.80 \pm 0.81$ & $4.74 \pm 0.84$ & 0.011 \\
\hline HDL cholesterol, mmol/L & $1.27 \pm 0.27$ & $1.48 \pm 0.33$ & $<0.001$ \\
\hline Triglyceride, mmol/L & $1.4(1.0-2.1)$ & $1.0(0.7-1.4)$ & $<0.001$ \\
\hline AST, U/L & $22.7 \pm 7.9$ & $19.6 \pm 6.3$ & $<0.001$ \\
\hline ALT, U/L & $26.3 \pm 15.8$ & $17.2 \pm 10.0$ & $<0.001$ \\
\hline GGT, U/L & $31(21-48)$ & $15(12-20)$ & $<0.001$ \\
\hline Uric acid, $\mu \mathrm{mol} / \mathrm{L}$ & $344.7 \pm 71.5$ & $249.1 \pm 55.1$ & $<0.001$ \\
\hline \multicolumn{4}{|l|}{ CRP concentration, mg/L } \\
\hline Arithmetic mean, mg/L & $1.17 \pm 1.34$ & $0.84 \pm 1.20$ & $<0.001$ \\
\hline Geometric mean, mg/L & $0.76 \pm 2.48$ & $0.49 \pm 2.60$ & $<0.001$ \\
\hline Median, mg/L & $0.72(0.40-1.43)$ & $0.45(0.25-0.98)$ & $<0.001$ \\
\hline Current smoking, \% & 40.7 & 5.3 & $<0.001$ \\
\hline Alcohol ingestion ${ }^{c}, \%$ & 51.3 & 7.5 & $<0.001$ \\
\hline Physical activity ${ }^{d}, \%$ & 28.1 & 50.9 & $<0.001$ \\
\hline Hypertension ${ }^{\mathrm{e}}, \%$ & 32.1 & 22.8 & $<0.001$ \\
\hline Diabetes $^{f}, \%$ & 6.7 & 3.4 & $<0.001$ \\
\hline
\end{tabular}

BMI, body mass index; SBP, systolic blood pressure; DBP, diastolic blood pressure; FPG, fasting plasma glucose; HDL, high density lipoprotein; AST, aspartate aminotransferase; ALT, alanine aminotransferase; GGT, $\gamma$-glutamyltransferase; CRP, Creactive protein. ${ }^{a}$ Values are presented as mean $\pm S D$, median (interquartile range), or percentage; ${ }^{b} p$-value was calculated by comparing men and women using t-test, Wilcoxon-Rank sum test, or $\chi^{2}$-test; ${ }^{c}$ alcohol drinking $\geq 20 \mathrm{~g} /$ day; ${ }^{\mathrm{d}}$ regular exercise $\geq$ once/week; ${ }^{e}$ hypertension was defined as $\mathrm{SBP} \geq 140 \mathrm{~mm} \mathrm{Hg}$, and/or DBP $\geq 90 \mathrm{~mm} \mathrm{Hg}$, or history of the disorder; ${ }^{\mathrm{f}}$ diabetes was defined as fasting plasma glucose level $\geq 7.0 \mathrm{mmol} / \mathrm{L}$ or a history of the disorder.

and HDL cholesterol for both men and women, whereas cigarette smoking correlated only in men. In multivariate regression analysis, age, male gender, cigarette smoking, physical activity, BMI, total cholesterol, HDL cholesterol, GGT, and uric acid were positively associated with CRP concentrations, whereas physical activity and HDL cholesterol were inversely associated with CRP concentrations (Table 5).

\section{Discussion}

In this cross-sectional study, we examined gender differences and determinants of CRP concentrations in
Korean adults. The distribution of CRP was highly skewed toward lower concentrations with long right tail. Although $\sim 30 \%$ of the US population has CRP concentrations $>3 \mathrm{mg} / \mathrm{L}(6)$, only $8.7 \%$ of men and $5.9 \%$ of women were found to fall into the high-risk category with CRP concentrations $>3.0 \mathrm{mg} / \mathrm{L}$. This finding suggests that CRP is lower in Korean adults, which might explain the lower coronary disease event rate in Korea. As previously mentioned, the CDC and AHA have recommended categorizing subjects using CRP cut-off thresholds of $<1.0,1.0-3.0$, and $>3.0$ $\mathrm{mg} / \mathrm{L}$ into low-, average-, and high-risk categories, respectively. These recommendations are based primarily on findings obtained from Western popula-

Table 2 Distribution of CRP concentration by age group and gender.

\begin{tabular}{|c|c|c|c|c|c|c|c|c|}
\hline & \multirow[t]{2}{*}{$\mathrm{n}$} & \multicolumn{7}{|c|}{ Percentile } \\
\hline & & 5 & 10 & 25 & 50 & 75 & 90 & 95 \\
\hline \multicolumn{9}{|l|}{ Men, years } \\
\hline$<40$ & 575 & 0.18 & 0.23 & 0.38 & 0.67 & 1.42 & 2.47 & 4.39 \\
\hline $40-49$ & 846 & 0.20 & 0.25 & 0.41 & 0.71 & 1.46 & 2.82 & 4.10 \\
\hline $50-59$ & 575 & 0.21 & 0.26 & 0.41 & 0.72 & 1.36 & 2.45 & 3.94 \\
\hline$\geq 60$ & 252 & 0.23 & 0.29 & 0.47 & 0.85 & 1.62 & 3.55 & 5.32 \\
\hline Total & 2248 & 0.19 & 0.25 & 0.40 & 0.72 & 1.43 & 2.71 & 4.16 \\
\hline \multicolumn{9}{|l|}{ Women, years } \\
\hline$<40$ & 838 & 0.11 & 0.13 & 0.20 & 0.34 & 0.66 & 1.53 & 2.76 \\
\hline $40-49$ & 926 & 0.13 & 0.15 & 0.23 & 0.38 & 0.82 & 1.76 & 2.65 \\
\hline $50-59$ & 639 & 0.17 & 0.22 & 0.33 & 0.61 & 1.29 & 2.60 & 4.72 \\
\hline$\geq 60$ & 272 & 0.19 & 0.25 & 0.39 & 0.72 & 1.73 & 3.10 & 4.17 \\
\hline Menopause (-) & 1746 & 0.12 & 0.15 & 0.21 & 0.35 & 0.63 & 1.26 & 1.95 \\
\hline Menopause $(+)$ & 929 & 0.17 & 0.21 & 0.32 & 0.59 & 1.45 & 3.08 & 4.45 \\
\hline Total & 2675 & 0.13 & 0.16 & 0.25 & 0.45 & 0.98 & 2.14 & 3.62 \\
\hline
\end{tabular}

The percentiles are calculated from each subgroup. 
A

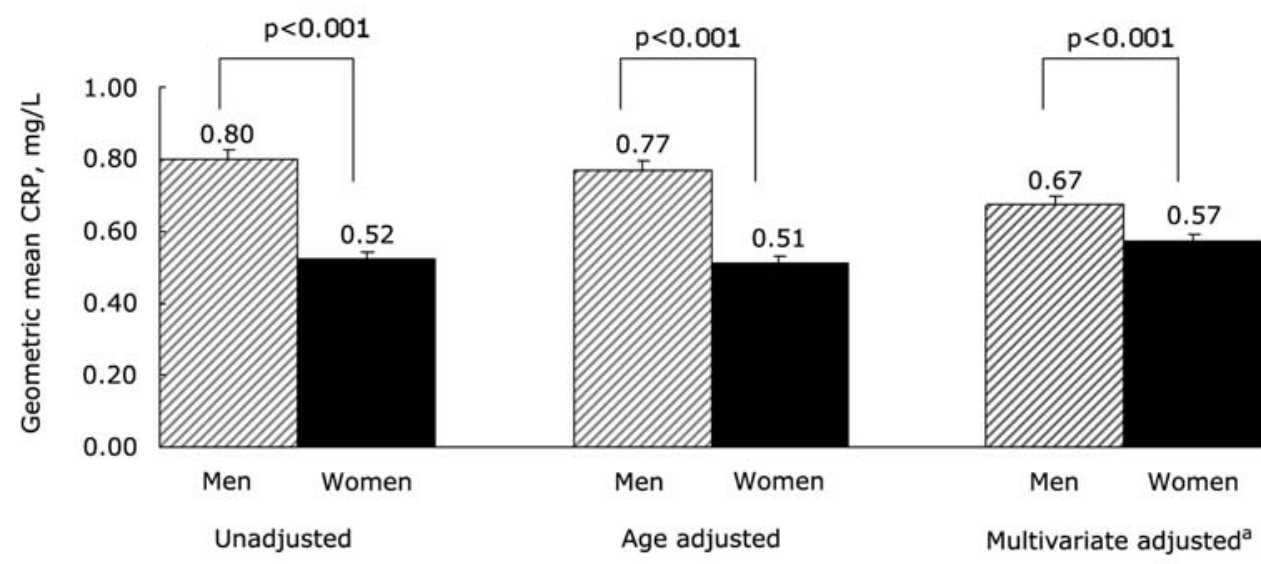

B

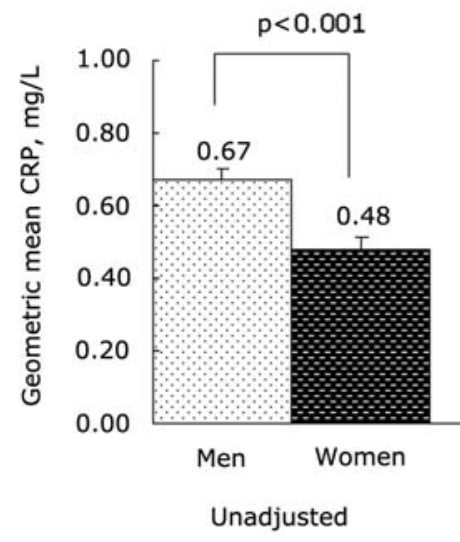

Non-smokers

$\mathrm{p}<0.001$
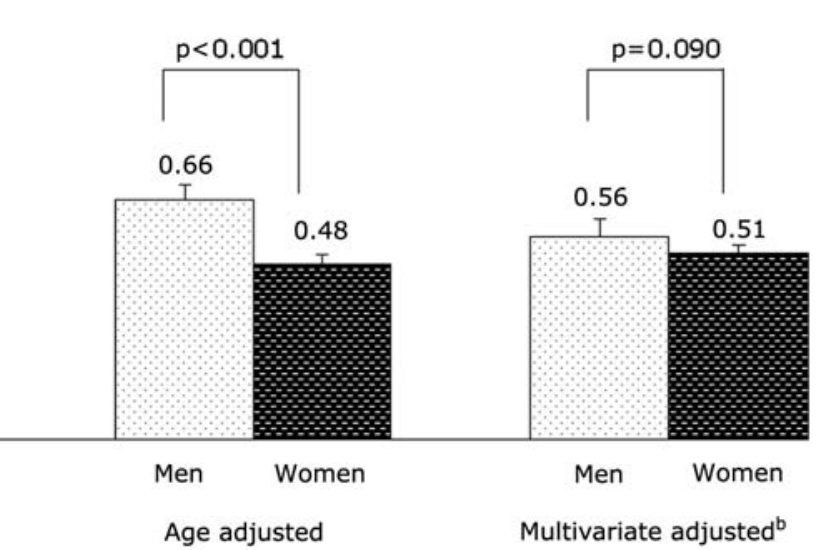

Figure 1 Adjusted geometric mean CRP level in men and women for the entire study population (A) and non-smokers (B). ${ }^{a}$ Adjusted for age, BMI, smoking status, alcohol intake, exercise, blood pressure, fasting plasma glucose, total cholesterol, triglyceride and HDL cholesterol; badjusted for age, BMI, alcohol intake, physical activity, blood pressure, fasting plasma glucose, total cholesterol, triglyceride and HDL cholesterol; bars show mean standard errors.

tions. Although the study population is not representative of the general population of Korea, the cut-off threshold for the high-risk tertile of CRP concentrations corresponds to $1.01 \mathrm{mg} / \mathrm{L}$ in men and $0.62 \mathrm{mg} / \mathrm{L}$ in women, based on the current study population. Some observational studies have shown that CRP concentrations are lower in East Asians compared with Westerners. Multiethnic studies in the US and Canada have shown that Chinese and Japanese have lower CRP concentrations compared to Western and aboriginal populations $(17,18)$. Several observa-

Table 3 Proportion of subjects with low-, intermediate-, and high-risk CRP concentrations according to the CDC/AHD cutoff thresholds.

\begin{tabular}{lcccc}
\hline $\mathrm{n}, \%$ & \multicolumn{4}{l}{ CRP categories } \\
\cline { 2 - 5 } & $<1.0 \mathrm{mg} / \mathrm{L}$ & $1.0-3.0 \mathrm{mg} / \mathrm{L}$ & $>3.0 \mathrm{mg} / \mathrm{L}$ & $\mathrm{p}$-Value \\
\hline Total & $3448(70.1)$ & $1117(22.7)$ & $353(7.2)$ & $<0.001$ \\
Men & $1418(63.1)$ & $635(28.3)$ & $195(8.7)$ & \\
Women & $2033(76.0)$ & $484(18.1)$ & $158(5.9)$ & \\
\hline
\end{tabular}

CRP, C-reactive protein. ${ }^{\mathrm{a}} \mathrm{p}$-Value was calculated by comparing men and women using $\chi^{2}$-test. tional studies suggest that CRP concentrations may be lower in East Asians compared to Westerners. Lee et al. (16) reported that the Chinese had the lowest CRP concentrations when compared to Caucasians, African Americans, and Hispanics. In another multiethnic study in Canada, Anand et al. (17) suggested that the Chinese had the lowest median CRP concentrations $(0.69 \mathrm{mg} / \mathrm{L})$ when compared to European $(1.24 \mathrm{mg} / \mathrm{L})$, South Asian (1.80 mg/L), and aboriginal populations $(4.20 \mathrm{mg} / \mathrm{L})$ in Canada. Similar results were reported by the Study of Women's Health Across the Nation (SWAN) cohort in the US where Chinese $(0.7 \mathrm{mg} / \mathrm{L})$ and Japanese $(0.5 \mathrm{mg} / \mathrm{L})$ had lower median CRP concentrations compared with Caucasians (1.4 mg/L), African Americans $(3.0 \mathrm{mg} / \mathrm{L})$, and Hispanics (2.3 mg/L) (17). These ethnic differences in CRP concentrations may be explained by genetic polymorphisms, diet, and lifestyle differences, which have been shown to affect inflammatory response (10-13, 19).

In the present study, CRP concentrations were higher in men compared with women, suggesting that male gender is a strong independent determinant of 
Table 4 Correlation between log-transformed CRP and various parameters.

\begin{tabular}{|c|c|c|c|c|}
\hline & \multicolumn{2}{|l|}{ Men } & \multicolumn{2}{|l|}{ Women } \\
\hline & $r$ & $p$-Value & $r$ & p-Value \\
\hline Age, years & 0.063 & 0.002 & 0.259 & $<0.001$ \\
\hline $\mathrm{BMI}, \mathrm{kg} / \mathrm{m}^{2}$ & 0.267 & $<0.001$ & 0.385 & $<0.001$ \\
\hline $\mathrm{SBP}, \mathrm{mm} \mathrm{Hg}$ & 0.060 & 0.004 & 0.140 & $<0.001$ \\
\hline $\mathrm{DBP}, \mathrm{mm} \mathrm{Hg}$ & 0.068 & 0.001 & 0.130 & $<0.001$ \\
\hline $\mathrm{FPG}, \mathrm{mmol} / \mathrm{L}$ & 0.075 & $<0.001$ & 0.206 & $<0.001$ \\
\hline Total cholesterol, $\mathrm{mmol} / \mathrm{L}$ & 0.054 & 0.009 & 0.183 & $<0.001$ \\
\hline HDL cholesterol, mmol/L & -0.264 & $<0.001$ & -0.263 & $<0.001$ \\
\hline Triglyceride, mmol/L & 0.146 & $<0.001$ & 0.298 & $<0.001$ \\
\hline $\mathrm{AST}, \mathrm{U} / \mathrm{L}$ & 0.147 & $<0.001$ & 0.188 & $<0.001$ \\
\hline $\mathrm{ALT}, \mathrm{U} / \mathrm{L}$ & 0.177 & $<0.001$ & 0.216 & $<0.001$ \\
\hline GGT, U/L & 0.209 & $<0.001$ & 0.128 & $<0.001$ \\
\hline Uric acid, $\mu \mathrm{mol} / \mathrm{L}$ & 0.205 & $<0.001$ & 0.274 & $<0.001$ \\
\hline Current smoker, \% & 0.122 & $<0.001$ & 0.221 & 0.221 \\
\hline Alcohol ingestion ${ }^{a}, \%$ & -0.042 & 0.045 & -0.036 & 0.927 \\
\hline Physical activity ${ }^{b}, \%$ & 0.030 & 0.149 & 0.018 & 0.056 \\
\hline
\end{tabular}

BMI, body mass index; SBP, systolic blood pressure; DBP, diastolic blood pressure; FPG, fasting plasma glucose; HDL, high density lipoprotein; AST, aspartate aminotransferase; ALT, alanine aminotransferase; GGT, $\gamma$-glutamyltransferase; CRP, Creactive protein. ${ }^{a}$ Alcohol drinking $\geq 20 \mathrm{~g} /$ day; ${ }^{b}$ regular exercise $\geq$ once/week. Coefficients $(r)$ and $p$-value were calculated using Pearson's correlation analysis for continuous variables and Spearman-Rank correlation for cigarette smoking, alcohol ingestion, and physical activity.

CRP concentrations. There is conflicting evidence concerning relative CRP concentrations in men and women. Some data from European populations have shown similar CRP concentrations in men and women $(8,20)$. In that study, the median CRP concentrations in men and women were similar (men, $1.52 \mathrm{mg} / \mathrm{L}$; women, $1.50 \mathrm{mg} / \mathrm{L}$ ). Data from Northern European populations (France, West Germany, and Scotland) and Southern European populations (Spain and Mediterranean countries) have also shown similar distributions of CRP concentrations with a median of $1.5 \mathrm{mg} / \mathrm{L}$ for both genders $(8,19)$. On the contrary, in two large multiethnic studies in the US, women had higher CRP concentrations, irrespective of race $(9,21)$. To date, relatively little has been written regarding the comparison of gender differences in CRP concentrations among East Asians. Yamada et al. reported in a Jichi Medical School Cohort Study, consisting of 2275 men and 3832 women in Japan, that men have higher CRP concentrations (9). Consistent with the results seen in Japanese, men in the current study have higher CRP concentrations compared with women. An observational study of Chinese subjects showed no difference in CRP concentrations with respect to gender (22). Contrary to our study and the Jichi Medical School study, the Chinese cohort was comprised of older men and women aged 50-70 years. Therefore, the relatively higher proportion of postmenopausal women may have influenced CRP concentrations. Although the reason for these discrepancies in CRP concentrations with respect to gender is unclear, there are some possible explanations. Differences in lifestyle and metabolic risk factors between men and women in each study population may affect CRP concentrations. In fact, in our study, men usually had more undesirable risk factors for atherosclerosis such as cigarette smoking, alcohol intake, obesity, hypertension, and diabetes when compared to women. These risk factors can be important contributors to chronic low-grade inflammation. Although gender dif-

Table 5 Results of multiple linear regression analysis to assess independent relationships between log-transformed CRP and clinical variables ${ }^{\mathrm{a}}$.

\begin{tabular}{|c|c|c|c|}
\hline Variables & Parameter, $\beta$ & SE & $\mathrm{p}$-Value \\
\hline Age, per 10 years & 0.099 & 0.014 & $<0.001$ \\
\hline Male gender & 0.127 & 0.038 & $<0.001$ \\
\hline $\mathrm{BMI}, \mathrm{kg} / \mathrm{m}^{2}$ & 0.060 & 0.005 & $<0.001$ \\
\hline Current smoking & 0.132 & 0.039 & $<0.001$ \\
\hline Physical activity ${ }^{b}$ & -0.061 & 0.027 & 0.027 \\
\hline $\mathrm{FPG}, \mathrm{mmol} / \mathrm{L}$ & 0.032 & 0.014 & 0.023 \\
\hline Total cholesterol, $\mathrm{mmol} / \mathrm{L}$ & 0.067 & 0.017 & $<0.001$ \\
\hline HDL cholesterol, mmol/L & -0.584 & 0.050 & $<0.001$ \\
\hline GGT, per $10 \mathrm{U} / \mathrm{L}$ & 0.056 & 0.008 & $<0.001$ \\
\hline Uric acid, per $10 \mu \mathrm{mol} / \mathrm{L}$ & 0.020 & 0.002 & $<0.001$ \\
\hline
\end{tabular}

BMI, body mass index; FPG, fasting plasma glucose; HDL, high density lipoprotein; GGT, $\gamma$-glutamyltransferase. Variables significantly associated with CRP concentrations are shown in the table. ${ }^{2}$ Multivariate linear regression analysis included age, gender, BMI, SBP, DBP, fasting plasma glucose, total cholesterol, HDL cholesterol, triglycerides, AST, ALT, GGT, uric acid, current history of cigarette smoking and alcohol ingestion, and physical activity as independent variables; ${ }^{b}$ regular exercise $\geq$ once/week. 
ferences with respect to CRP concentrations remained valid in multivariate adjusted ANCOVA test, there appeared to be no significant difference in the subgroup analyses for non-smokers. This suggests that gender differences may not be due to gender itself, but rather a reflection of different cardiovascular risk factors. In addition, the proportion of patients using estrogen was different in each study population. CRP is known to be increased in women taking estrogen (23). To avoid the confounding factor of drug use, subjects taking estrogen replacement therapy or oral contraceptives were excluded from our study.

In the multivariate model, CRP concentrations were significantly associated with several metabolic variables including $\mathrm{BMI}$, total cholesterol, and $\mathrm{HDL}$ cholesterol. These findings are consistent with current knowledge regarding metabolic disturbances and inflammatory markers (10-12). The positive association of CRP with BMI may be explained by the effects of proinflammatory cytokines including interleukin- 6 (IL-6) and tumor necrosis factor- $\alpha$ (TNF- $\alpha$ ), which are expressed in adipose tissue and stimulate hepatic production of CRP $(24,25)$. Several mechanisms may explain the significant relationship between cigarette smoking and CRP concentrations. Cigarette smoking promotes inflammation in the oral cavity and airway tract, leading to periodontitis and chronic bronchitis $(26,27)$. Also, free radicals generated by cigarette smoking can induce the production of inflammatory cytokines and consequently elevate CRP concentrations, as mentioned earlier (28). We also found an inverse relationship between CRP and physical activity. Regular exercise may have a favorable effect on suppressing abdominal fat accumulation and inflammatory markers (29). Serum CRP concentrations were also associated with biomarkers such as serum GGT and uric acid, which are known to be surrogate markers of adverse cardiovascular events and mortality $(16,30)$. This finding is consistent with emerging evidence that increased GGT and uric acid are strongly linked to chronic low-grade inflammation $(16,30)$.

There are several limitations of the current study. First, because study subjects were volunteers for health promotion screening at a single hospital, and appeared to be slightly healthier compared to community-based cohorts, the study population may not be representative of the general Korean population. Therefore, this study may have been affected by the selection bias. Second, the CDC and AHA guidelines recommend two separate CRP measurements for determining within individual variability (6). However, only one measurement of CRP was included in the analysis and it was not possible to determine whether an acute and brief episode of infection or chronic inflammation was responsible for the correlation observed. To minimize these random errors, we excluded subjects with CRP values $\geq 10 \mathrm{mg} / \mathrm{L}$. Third, we lacked information on the measurement of abdominal adiposity and waist circumference. Consequently, we could not determine exactly whether the association of CRP with BMI depended on overall adiposity or distribution pattern. Finally, we did not take into consideration the effect of other potential confounding variables on CRP concentrations such as socioeconomic status, diet pattern, medication history and use of potential anti-inflammatory agents [aspirin, other non-steroidal anti-inflammatory drugs (NSAIDs), angiotensin-converting enzyme (ACE) inhibitors, and 3-hydroxy-3-methylglutaryl coenzyme A (HMG-CoA) reductase inhibitors].

Despite these limitations, given the increasing use of CRP as a valuable predictor of CVD, our findings may have important clinical implications in terms of preventive cardiovascular risk strategies in Korea.

In summary, CRP distributions and gender differences in Koreans are different from previous Western studies, although similar risk factors influence CRP concentrations. Our results suggest that ethnicity and gender specific cut-off thresholds for CRP should be taken into consideration in CVD risk assessment. Future prospective studies are warranted to assess how different CRP distributions influence CVD risk prediction in Korean adults.

\section{Acknowledgements}

The authors would like to thank Ms. Sydney Sue Kim for her help in editing the manuscript.

\section{References}

1. Ross R. Atherosclerosis - an inflammatory disease. N Engl J Med 1999;340:115-26.

2. Libby $P$, Ridker PM, Maseri A. Inflammation and atherosclerosis. Circulation 2002;105:1135-43.

3. Ridker PM, Buring JE, Cook NR, Rifai N. C-reactive protein, the metabolic syndrome, and risk of incident cardiovascular events: an 8-year follow-up of 14,719 initially healthy American women. Circulation 2003;107:391-7.

4. Danesh J, Wheeler JG, Hirschfield GM, Eda S, Eiriksdottir G, Rumley A, et al. C-reactive protein and other circulating markers of inflammation in the prediction of coronary heart disease. N Engl J Med 2004;350:1387-97.

5. Strandberg TE, Tilvis RS. C-reactive protein, cardiovascular risk factors, and mortality in a prospective study in the elderly. Arterioscler Thromb Vasc Biol 2000;20: 1057-60.

6. Pearson TA, Mensah GA, Alexander RW, Anderson JL, Cannon RO 3rd, Criqui M, et al. Markers of inflammation and cardiovascular disease: application to clinical and public health practice: a statement for healthcare professionals from the Centers for Disease Control and Prevention and the American Heart Association. Circulation 2003;107:499-511.

7. Rifai N, Ridker PM. Population distribution of C-reactive protein in apparently healthy men and women in the United States: implication for clinical interpretation. Clin Chem 2003;49:666-9.

8. Imhof A, Fröhlich M, Loewel H, Helbecque N, Woodward $\mathrm{M}$, Amouyel $\mathrm{P}$, et al. Distribution of $\mathrm{C}$-reactive protein measured by high-sensitivity assays in apparently healthy men and women from different populations in Europe. Clin Chem 2003;49:669-72.

9. Yamada S, Gotoh T, Nakashima Y, Kayaba K, Ishikawa S, Nago $N$, et al. Distribution of serum C-reactive protein and its association with atherosclerotic risk factors in a Japa- 
nese population: Jichi Medical School Cohort Study. Am J Epidemiol 2001;153:1183-90.

10. Khera A, McGuire DK, Murphy SA, Stanek HG, Das SR, Vongpatanasin $\mathrm{W}$, et al. Race and gender differences in C-reactive protein levels. J Am Coll Cardiol 2005;2:464-9.

11. Rogowski O, Zeltser D, Shapira I, Burke M, Zakut V, Mardi T, et al. Gender difference in C-reactive protein concentrations in individuals with atherothrombotic risk factors and apparently healthy ones. Biomarkers 2004; 9:85-92.

12. Gallop Korea. Cigarette smoking survey among adults. Seoul, South Korea: The Korea Gallup Report, 2004.

13. MacGregor AJ, Gallimore JR, Spector TD, Pepys MB. Genetic effects on baseline values of C-reactive protein and serum amyloid a protein: a comparison of monozygotic and dizygotic twins. Clin Chem 2004;50:978-9.

14. Wener MH, Daum PR, McQuillan GM. The influence of age, sex, and race on the upper reference limit of serum C-reactive protein concentration. J Rheumatol 2000;27: 2351-9.

15. Ford ES, Giles WH, Mokdad AH, Myers GL. Distribution and correlates of $\mathrm{C}$-reactive protein concentrations among adult US women. Clin Chem 2004;50:574-81.

16. Lee YJ, Kim JK, Lee JH, Lee HR, Kang DR, Shim JY. Association of serum r-glutamyltransferase with C-reactive protein levels and white blood cell count in Korean adults. Clin Chem Lab Med 2008;46:1410-5.

17. Anand SS, Razak F, Yi Q, Davis B, Jacobs R, Vuksan V, et al. C-reactive protein as a screening test for cardiovascular risk in a multiethnic population. Arterioscler Thromb Vasc Biol 2004;24:1509-15.

18. Matthews KA, Sowers MF, Derby CA, Stein E, MiracleMcMahill H, Crawford SL, et al. Ethnic differences in cardiovascular risk factor burden among middle-aged women: Study of Women's Health Across the Nation (SWAN). Am Heart J 2005;149:1066-73.

19. Araújo F, Pereira AC, Mota GF, Latorre Mdo R, Krieger $\mathrm{JE}$, Mansur AJ. The influence of tumor necrosis factor308 and C-reactive protein G1059C gene variants on serum concentration of $\mathrm{C}$-reactive protein: evidence for an age-dependent association. Clin Chim Acta 2004; $349: 129-34$
20. García-Lorda P, Bulló $M$, Balanzà R, Salas-Salvadó J. C-reactive protein, adiposity and cardiovascular risk factors in a Mediterranean population. Int J Obes 2006; 30:468-74.

21. Lakoski SG, Cushman M, Criqui M, Rundek T, Blumenthal RS, D'Agostino RB Jr, et al. Gender and C-reactive protein: data from the Multiethnic Study of Atherosclerosis (MESA) cohort. Am Heart J 2006;152:593-8.

22. Ye X, Yu Z, Li H, Franco OH, Liu Y, Lin X. Distributions of $\mathrm{C}$-reactive protein and its association with metabolic syndrome in middle-aged and older Chinese people. J Am Coll Cardiol 2007;49:1798-805.

23. Ridker PM, Hennekens CH, Rifai N, Buring JE, Manson JE. Hormone replacement therapy and increased plasma concentration of C-reactive protein. Circulation 1999; 100:713-6.

24. Hotamisligil GS, Arner P, Caro JF, Atkinson RL, Spiegelman BM. Increased adipose tissue expression of tumor necrosis factor-alpha in human obesity and insulin resistance. J Clin Invest 1995;95:2409-15.

25. Ronti T, Lupattelli G, Mannarino E. The endocrine function of adipose tissue: an update. Clin Endocrinol 2006; 64:355-65.

26. Fredriksson MI, Figueredo $C M$, Gustafsson $A$, Bergström $\mathrm{KG}$, Asman BE. Effect of periodontitis and smoking on blood leukocytes and acute-phase proteins. J Periodontol 1999;70:1355-60.

27. Maestrelli $P$, Saetta M, Mapp CE, Fabbri LM. Remodeling in response to infection and injury. Airway inflammation and hypersecretion of mucus in smoking subjects with chronic obstructive pulmonary disease. Am J Respir Crit Care Med 2001;164:S76-80.

28. Tappia PS, Troughton KL, Langley-Evans SC, Grimble RF. Cigarette smoking influences cytokine production and antioxidant defences. Clin Sci 1995;88:485-9.

29. Albert MA, Glynn RJ, Ridker PM. Effect of physical activity on serum C-reactive protein. Am J Cardiol 2004;93: 221-5.

30. Kanellis J, Kang DH. Uric acid as a mediator of endothelial dysfunction, inflammation, and vascular disease. Semin Nephrol 2005;25:39-42. 